\title{
User Experience Evaluation Methods in Product Development (UXEM'09)
}

\author{
Virpi Roto $^{1,2}$, Kaisa Väänänen-Vainio-Mattila ${ }^{2,1}$, \\ Effie Law ${ }^{3}$, and Arnold Vermeeren ${ }^{4}$ \\ ${ }^{1}$ Nokia Research Center, P.O.Box 407, 00045 Nokia Group, Finland \\ virpi.roto@nokia.com \\ ${ }^{2}$ Tampere University of Technology, Human-Centered Technology, \\ Korkeakoulunkatu 6, 33720 Tampere, Finland \\ kaisa.vaananen-vainio-mattila@tut.fi \\ ${ }^{3}$ University of Leicester, LE1 7RH Leicester, U.K. \\ elaw@mcs.le.ac.uk \\ ${ }^{4}$ Delft University of Technology, Industrial Design Engineering, \\ Landbergstraat 15, 2628 CE Delft, The Netherlands \\ a.p.o.s.vermeeren@tudelft.nl
}

\begin{abstract}
High quality user experience (UX) has become a central competitive factor of product development in mature consumer markets [1]. Although the term UX originated from industry and is a widely used term also in academia, the tools for managing UX in product development are still inadequate. A prerequisite for designing delightful $\mathrm{UX}$ in an industrial setting is to understand both the requirements tied to the pragmatic level of functionality and interaction and the requirements pertaining to the hedonic level of personal human needs, which motivate product use [2]. Understanding these requirements helps managers set UX targets for product development. The next phase in a good usercentered design process is to iteratively design and evaluate prototypes [3]. Evaluation is critical for systematically improving UX. In many approaches to UX, evaluation basically needs to be postponed until the product is fully or at least almost fully functional. However, in an industrial setting, it is very expensive to find the UX failures only at this phase of product development. Thus, product development managers and developers have a strong need to conduct UX evaluation as early as possible, well before all the parts affecting the holistic experience are available. Different types of products require evaluation on different granularity and maturity levels of a prototype. For example, due to its multi-user characteristic, a community service or an enterprise resource planning system requires a broader scope of UX evaluation than a microwave oven or a word processor that is meant for a single user at a time. Before systematic UX evaluation can be taken into practice, practical, lightweight UX evaluation methods suitable for different types of products and different phases of product readiness are needed. A considerable amount of UX research is still about the conceptual frameworks and models for user experience [4]. Besides, applying existing usability evaluation methods (UEMs) without adaptation to evaluate UX may lead to some scoping issues. Consequently, there is a strong need to put UX evaluation from research into practice.
\end{abstract}

Keywords: User experience, Evaluation methods, User-centered design, Product development. 


\section{Goals of the Workshop}

This workshop will primarily focus on concrete and pragmatic UX evaluation methods, but the UX models developed in academic research will act as ground for the methodological discussion. The aim is to transfer knowledge in both directions: To enable academics to gain knowledge about real problems in evaluating UX, and enable practitioners to get informed and inspired by academics with knowledge about UX factors, models and theories.

The overview of UX evaluation methods and techniques resulting from the previous UXEM'08 workshop [5] and from a SIG session in CHI'09 conference [6] will be used as a starting point. The envisaged main result of the current workshop is a consolidated mapping which shows UX evaluation methods along the product development and product readiness phases. Additionally, challenges and gaps in UX research relevant for UX evaluation will be listed to guide further UX research.

To achieve this, the emphasis in the accepted position papers will be on concrete UX evaluation case studies, but some more theoretical papers will also be accepted. In addition, a list of UX elements and a basic model of product development will be used as a basis for the discussion and group work sessions during the workshop. The questions explored in the workshop cover:

- What experiential evaluation methods are available or under development? What methods from related disciplines, such as arts, industrial design, psychology, sociology, and marketing, could be utilized in UX evaluation?

- What is the applicability of different evaluation methods in different product development phases and product readiness stages?

- How does UX of different application fields - such as mobile consumer services or devices, games, harvester machines, or financial applications - and usage contexts differ? How should the evaluation approaches be adapted for different cases?

Results of this workshop will be applicable as a guideline for UX researchers and practitioners in product development.

\section{References}

1. Pine, J., Gilmore, J.H.: The Experience Economy: Working is Theatre \& Every Business a Stage. Harvard Business School Press, Boston (1999)

2. Hassenzahl, M.: The thing and I: understanding the relationship between user and product. In: Blythe, M., Overbeeke, C., Monk, A.F., Wright, P.C. (eds.) Funology: From Usability to Enjoyment, pp. 31-42. Kluwer, Dordrecht (2003)

3. ISO 13407:1999, Human-Centred Design Proceses for Interactive Systems. International Standardization Organization (ISO), Switzerland

4. COST294-MAUSE, Workshop on User Experience - Towards a Unified View. In: conjunction with NordiCHI, conference, Oslo, Norway (2006), http: / /www . cost294 . org /

5. Väänänen-Vainio-Mattila, K., Roto, V., Hassenzahl, M.: Now Let's Do It in Practice: User Experience Evaluation Methods in Product Development. In: CHI 2008 Proceedings - Workshops, Florence, Italy, April 6, 2008, pp. 3961-3964 (2008), http: / /www. cs.tut.fi/ ihte/CHI08_workshop/slides/Poster_UXEM_CHI08_V1.1.pdf

6. Obrist, M., Roto, V., Väänänen-Vainio-Mattila, K.: User Experience Evaluation: Do You Know Which Method to Use? A special interest group session. In: Extended abstracts of CHI 2009 conference (2009) 